\title{
Acceleration Mechanism of Nucleation of Polymers by Nano-sizing of Nucleating Agent
}

\author{
Tsuyoshi Urushinara,,${ }^{1, \dagger}$ Kiyoka OKadA, ${ }^{2}$ Kaori Watanabe, ${ }^{2}$ Akihiko Toda, ${ }^{2}$ \\ Etsuo ToBita, ${ }^{1}$ Naoshi KAwAMOTO, ${ }^{1}$ and Masamichi HikOSAKA ${ }^{2}$ \\ ${ }^{1}$ ADEKA Corporation, 5-2-13 Shirahata, Minami-ku, Saitama 336-0022, Japan \\ ${ }^{2}$ Graduate School of Integrated Arts and Sciences, Hiroshima University, \\ 1-7-1 Kagamiyama, Higashihiroshima 739-8521, Japan
}

(Received May 22, 2006; Accepted October 26, 2006; Published December 7, 2006)

\begin{abstract}
Role of nucleating agent (NA) in nucleation mechanism of polymers was solved based on kinetic study. Theoretical prediction in our previous study that $I \propto C_{\mathrm{NA}} a_{\mathrm{NA}}^{-1}$ (1) was experimentally confirmed by changing $C_{\mathrm{NA}}$ and $a_{\mathrm{NA}}$, where $I$ is nucleation rate of polymers, $C_{\mathrm{NA}}$ is a concentration of NA in the mixture of NA and a polymer and $a_{\mathrm{NA}}$ is lateral size of a NA crystal. As the eq 1 is formulated by assuming an important role of epitaxy between NA and polymer crystals, the confirmation of eq 1 confirmed the essential role of the epitaxy in acceleration mechanism of nucleation of polymers. $a_{\mathrm{NA}}$ was decreased from the order of $\mu \mathrm{m}$ to $\mathrm{nm}$ and narrow distribution of $a_{\mathrm{NA}}\left(f\left(a_{\mathrm{NA}}\right)\right)$ was obtained by improving "bottom up" method. We have an important conclusion in polymer science and industries that decreasing $a_{\mathrm{NA}}$ from the order of $\mu \mathrm{m}$ to $\mathrm{nm}$ and narrowing $f\left(a_{\mathrm{NA}}\right)$ are the most effective methods to improve the performance of NA. [doi:10.1295/polymj.PJ2006040]

KEY WORDS Nucleating Agent / Nano / Epitaxy / Nucleation / Crystal / Polypropylene /
\end{abstract}

Nucleating agent (NA) is widely used industrially for improving performance of semicrystalline polymer materials, such as isotactic polypropylene (iPP). ${ }^{1,2} \mathrm{NA}$ accelerates nucleation rate $I$ and improves mechanical and optical properties of polymers. Reduction of processing time is also attributed to the effect of NA. Hikosaka et al. ${ }^{3}$ showed that the number density of crystals of polyethylene (PE) increased by $10^{4}$ times after adding NA, which enabled direct observation of nucleation by means of small angle X-ray scattering (SAXS). In this study sodium 2,2'-methylene-bis-(4,6-di-t-butylphenylene)phosphate (ADEKA Corp., NA-11) was mixed with PE. The concentration of NA was $3 \mathrm{wt} \%$. Improvement of properties of polymers by NA is the most effective way, because that is achieved by adding small amount of NA without modifying processing facilities. But we have not had a criterion for designing high-performance NA, because acceleration mechanism of nucleation of polymers by NA has not been solved well based on kinetic study. Clarification of the mechanism by NA is significant and interesting for polymer science and industries.

\section{Studies of "Epitaxy" between NA and Polymers}

Most nucleation from the bulky melt is heterogeneous nucleation. ${ }^{4}$ We will adopt in this study one possible definition of NA that the NA is a special heterogeneity which shows significantly strong epitaxy between NA crystal and nucleus. It is to be noted that all commercial NA are made of crystalline materials. ${ }^{5-10}$
Epitaxy between NA and polymer crystals was rather well structurally studied, ${ }^{11-15}$ but it has not been studied by kinetic study. Kawaguchi et al. ${ }^{15}$ showed the epitaxy between iPP and NA-11 by means of electron microscope and diffraction. They crystallized iPP crystals from the melt on a large single crystal of the NA. They showed a kind of fiber pattern of $\alpha$ form of iPP. The fiber axis was $c$ axis which was parallel to the $b$ axis of the NA crystal. Therefore $a$ and $b$ axes of iPP crystal were not oriented.

\section{$\Delta T$ Dependence of I}

Classical nucleation theory ${ }^{16}$ shows that $I$ is generally expressed by

$$
I=I_{0} \exp \left(-\frac{\Delta G^{*}}{k T_{c}}\right)
$$

where $I_{0}$ is a prefactor, $\Delta G^{*}$ is a free energy for forming a critical nucleus, $k$ is Boltzmann constant and $T_{c}$ is crystallization temperature. The $\Delta G^{*} \mathrm{~s}$ of the heterogeneous three dimensional (3D) and two dimensional (2D) nucleation ${ }^{4}$ are given by

$$
\Delta G^{*}=\frac{16 \sigma \sigma_{e} \Delta \sigma}{\Delta g^{2}} \text { for } \Delta g<2 \Delta \sigma
$$

and

$$
\Delta G^{*}=\frac{4 \sigma \sigma_{e}}{\Delta g-\Delta \sigma} \quad \text { for } \quad \Delta g \geq 2 \Delta \sigma
$$


respectively, where $\sigma$ and $\sigma_{e}$ are lateral and end surface free energy, respectively, $\Delta \sigma$ is defined by

$$
\Delta \sigma \equiv \sigma+\sigma_{0 s}-\sigma_{s}
$$

where $\sigma_{0 \mathrm{~s}}$ is interfacial free energy between the NA crystal and the nucleus, $\sigma_{\mathrm{s}}$ is surface free energy between the NA crystal and the melt, and $\Delta g$ is free energy of fusion. $\Delta g$ is given by

$$
\Delta g=\frac{\Delta h \Delta T}{T_{m}^{0}}
$$

where $\Delta h$ is enthalpy of fusion, $T_{m}{ }^{0}$ is equilibrium melting temperature, and $\Delta T$ is the degree of supercooling defined by

$$
\Delta T \equiv T_{m}^{0}-T_{c} .
$$

In this paper, $\sigma, \sigma_{\mathrm{e}}, \Delta \sigma, \Delta g$ and $\Delta h$ are defined per repeating unit.

All interactions between NA and polymer crystal, i.e., "epitaxy," should be reflected in $I_{0}$ and $\Delta G^{*}$ in eq 1 . The purpose of this study is to confirm $I_{0}$ dependence of $I$. $I_{0}$ will be formulated in the next section. As we will focus on the important role of epitaxy in $I_{0}$ in this study, the following approximation on $\Delta G^{*}$ was adopted. $\Delta G^{*}(\Delta \sigma)$ is related to efficiency of epitaxy which is basically controlled by lattice matching of NA and polymer crystals. Important role of epitaxy in $\Delta G^{*}$ dependence of $I$ on iPP with different NAs will be reported in the succeeding paper.

Eq 3 indicates that heterogeneous 2D nucleation takes place when $\Delta T$ is so large that $\Delta g$ is much larger than $2 \Delta \sigma$. As observed $\Delta T$ is several tens $\mathrm{K}$ in most polymer crystallization, the condition $\Delta g>$ $2 \Delta \sigma$ is usually satisfied. For example, as usual range of $\Delta T$ of iPP is between 30 and $60 \mathrm{~K}, \Delta g$ becomes 6 to 12 times as large as $\Delta \sigma$.

When $\Delta g \gg \Delta \sigma$ is satisfied, we can roughly approximate the eq 3 by

$$
\Delta G^{*} \cong \frac{4 \sigma \sigma_{e}}{\Delta g} \text { for } \quad \Delta g \gg \Delta \sigma .
$$

As the $\Delta G^{*}$ in eq 7 is not a function of $\Delta \sigma$, the epitaxy does not significantly affect the $\Delta G^{*}$. Therefore it is concluded that the epitaxy of NA affect $I_{0}$, while it does not significantly do $\Delta G^{*}$. In this study approximated eq 7 is used.

Insertion of eqs 5 and 7 into eq 1 leads the final formula,

$$
I \cong I_{0} \exp \left(-\frac{C}{\Delta T}\right)
$$

where

$$
C=\frac{4 \sigma \sigma_{e} T_{m}^{0}}{k T_{c} \Delta h}
$$

The Prediction of the Effect of NA on I

In our previous study, ${ }^{17}$ we predicted theoretically

$$
I \propto C_{\mathrm{NA}} a_{\mathrm{NA}}{ }^{-1}
$$

where $C_{\mathrm{NA}}$ is a concentration of NA in the mixture of NA and polymer and $a_{\mathrm{NA}}$ is the longest lateral size of NA crystal. The eq 10 is formulated by assuming the important role of epitaxy in heterogeneous nucleation. In this case, $I_{0}$ in eq 8 should be in proportion to surface area of a NA crystal $(A)$ and number density of NA crystal $\left(v_{\mathrm{NA}}\right)$, i.e.,

$$
I \propto I_{0} \propto A v_{\mathrm{NA}} .
$$

When we assume that all NAs have similar shape, $A$ is given by

$$
A \propto a_{\mathrm{NA}}^{2} .
$$

$v_{\mathrm{NA}}$ is defined by

$$
v_{\mathrm{NA}} \equiv M_{\mathrm{NA}} / m_{\mathrm{NA}}
$$

where $M_{\mathrm{NA}}$ is total weight of NA per unit volume and $m_{\mathrm{NA}}$ is weight of one NA crystal. $M_{\mathrm{NA}}$ and $m_{\mathrm{NA}}$ is written as

$$
M_{\mathrm{NA}} \propto C_{\mathrm{NA}} \text { and } m_{\mathrm{NA}} \propto a_{\mathrm{NA}}{ }^{3} .
$$

From the eqs 13 and 14, $v_{\mathrm{NA}}$ is given by

$$
v_{\mathrm{NA}} \propto C_{\mathrm{NA}} / a_{\mathrm{NA}}{ }^{3} .
$$

Substituting eqs 12 and 15 into eq 11 leads eq 10.

The purpose of this study is to confirm the prediction of eq 10 by controlling $a_{\mathrm{NA}}$ from the order of $\mathrm{nm}$ to $\mu \mathrm{m}$, which clarifies the assumption that the important role of epitaxy in heterogeneous nucleation. When $a_{\mathrm{NA}}$ is smaller (larger) than $0.1 \mu \mathrm{m}$, the NA is named "nano NA" ("macro NA") in this study.

\section{High-Performance NA for Polymers}

Eq 10 predicts that

$$
I \propto a_{\mathrm{NA}}^{-1} \text { for } C_{\mathrm{NA}}=\text { const. }
$$

i.e., the ability of NA increases in proportion to $a_{\mathrm{NA}}{ }^{-1}$. Therefore the ability of conventional NA for iPP is inefficient, because $a_{\mathrm{NA}}$ is in order $\mu \mathrm{m} .{ }^{18}$ If $a_{\mathrm{NA}}$ could be decreased from $1 \mu \mathrm{m}$ to $1 \mathrm{~nm}$, it is predicted that $I$ of iPP mixed with nano NA (I (nano NA) $\left(a_{\mathrm{NA}}=1 \mathrm{~nm}\right)$ will become $10^{3}$ times as large as that mixed with macro NA (I(macro NA)) $\left(a_{\mathrm{NA}}=1 \mu \mathrm{m}\right)$. The third purpose of this study is to develop significantly high-performance NA by producing nano-sized NA with sharp distribution.

\section{Nano NA}

Nano-sized crystal is usually crystallized by "bottom up" method, ${ }^{19}$ which means making crystals by crystallizing atoms or molecules from isotropic phase such as gas, solution or the melt. Two typical types of 
"bottom up" methods, spray drying and solution crystallization methods, were adopted in this study.

Spray Drying Method. Spray drying method is widely used for the particle production in the various industries such as chemicals, foods and medicines. Spray drying method can produce particles whose size is from the order of $\mathrm{nm}$ to $\mu \mathrm{m}$ by controlling concentration of solution or droplet size. ${ }^{20}$

Solution Crystallization Method. Solution crystallization can widely control $a_{\mathrm{NA}}$ from the order of $\mathrm{nm}$ to $\mathrm{cm}$ by controlling degree of supersaturation or diffusion of solutes.

\section{Macro NA}

Commercial NA is usually made of sufficiently large crystal by "top down" method. Top down method is usually mechanical grinding such as ball mill, jet mill and so on. The range of $a_{\mathrm{NA}}$ of commercial NA is between several sub $\mu \mathrm{m}$ and several tens $\mu \mathrm{m}$. It is difficult to decrease $a_{\mathrm{NA}}$ smaller than $0.1 \mu \mathrm{m}$, i.e. nano NA is difficult to be obtained.

\section{Purpose}

The purposes of this study are 1) to confirm the prediction experimentally in the previous study ${ }^{17}$ that the nucleation rate $I$ of polymers obeys the formula $I \propto C_{N A} a_{N A}{ }^{-1}$ (eq 1 ) by controlling lateral size of NA $a_{\mathrm{NA}}$ from the order of nm to $\left.\mu \mathrm{m}, 2\right)$ to confirm the important role of epitaxy in acceleration mechanism of nucleation of polymers and 3) to develop significantly high performance NA by making nano-sized NA with sharp distribution of $a_{\mathrm{NA}}, f\left(a_{\mathrm{NA}}\right)$.

\section{EXPERIMENTAL}

\section{Materials}

Typical NA of sodium 2,2'-methylene-bis-(4,6-di- $t$ butylphenylene)phosphate (ADEKA Corp., NA-11)
Table I. Parameters of iPP

\begin{tabular}{cc}
\hline$\Delta \sigma /$ J rep.u. $^{-1}$ & $1.71 \times 10^{-2221}$ \\
$\Delta h / \mathrm{J}$ rep.u. & -1 \\
$T_{m}{ }^{0} / \mathrm{K}$ & $1.53 \times 10^{-2022}$ \\
\hline
\end{tabular}

was used. Hereafter this crystalline material will be simply named "NA". Unit cell structure of NA belongs monoclinic system ${ }^{15}$ which we will name $\alpha$ form. Lattice parameters are $a=2.6438 \mathrm{~nm}, b=$ $0.608 \mathrm{~nm}, c=3.7172 \mathrm{~nm}, \beta=93.65^{\circ} .{ }^{15}$ As the most typical polymer, iPP $\left(M_{\mathrm{n}}=6.4 \times 10^{4}, M_{\mathrm{w}}=3.0 \times\right.$ $10^{5}, M_{\mathrm{w}} / M_{\mathrm{n}}=4.6$ and $\left.[\mathrm{mmmm}]=97 \%\right)$ was used. Parameters of iPP crystals used in this study are shown in Table I. ${ }^{21-25}$ Repeating unit of iPP was assumed that the direction of the folding is along (110).

\section{Preparation of NA}

$a_{\mathrm{NA}}$ was controlled by applying the following methods. Names of NA were listed in Table II.

Bottom Up Method 1 (Spray Drying Method). Figure 1 shows schematic illustration of spray drying method. Methanol solution of NA was sprayed into a tube by coaxial atomizing nozzle (Spraying Systems Co., 1/4JAU with PF1050 fluid cap and PA64 air cap). As the temperature in the tube was kept at $70^{\circ} \mathrm{C}$ and droplets were readily vaporized, NA crystallized from the solution during drying due to increase of the concentration of NA in the mixture of $\mathrm{NA}$ and $\mathrm{MeOH}\left(C_{\mathrm{NA} / \mathrm{MeOH}}\right)$. Assuming that one single crystal generates from one droplet, $a_{\mathrm{NA}}$ is given by

$$
a_{\mathrm{NA}}=\left(\frac{\rho_{\mathrm{MeOH}} C_{\mathrm{NA} / \mathrm{MeOH}}}{\rho_{\mathrm{NA}}}\right)^{\frac{1}{3}} x
$$

where $\rho_{\mathrm{MeOH}}, \rho_{\mathrm{NA}}$ and $x$ represent density of methanol $(\mathrm{MeOH})$ and NA and droplet size, respectively. $a_{\mathrm{NA}}$ can be decreased from the order of $\mu \mathrm{m}$ to $\mathrm{nm}$ by decreasing $C_{\mathrm{NA} / \mathrm{MeOH}}$ and/or $x$. In the coaxial atomizing

Table II. Name and characteristics of NA prepared by various methods

\begin{tabular}{|c|c|c|c|c|c|}
\hline & & Name of NA & $\overline{a_{N A}} / \mathrm{nm}$ & $s^{\mathrm{b})}$ & Comments \\
\hline \multirow{4}{*}{ Bottom up 1} & \multirow{4}{*}{ Spray drying } & Nano NA-1 & $26^{a)}$ & 0.73 & $C_{\mathrm{NA} / \mathrm{MeOH}}=10^{-5} \mathrm{wt} \%$ \\
\hline & & Nano NA-2 & $53^{\text {a) }}$ & 0.8 & $C_{\mathrm{NA} / \mathrm{MeOH}}=10^{-4}$ wt $\%$ \\
\hline & & Macro NA-1 & $1.5 \times 10^{2}$ a) & 0.33 & $C_{\mathrm{NA} / \mathrm{MeOH}}=10^{-2} \mathrm{wt} \%$ \\
\hline & & Macro NA-2 & $4.5 \times 10^{3 \mathrm{c})}$ & 0.44 & $C_{\mathrm{NA} / \mathrm{MeOH}}=34 \mathrm{wt} \%$ \\
\hline \multirow{2}{*}{ Bottom up 2} & \multirow{2}{*}{$\begin{array}{c}\text { Solution } \\
\text { crystallization }\end{array}$} & Nano NA-3 & $5^{\mathrm{d})}$ & - & $\begin{array}{l}C_{\mathrm{NA} /(n-\mathrm{BuOH}+\mathrm{xylene})}=0.38 \mathrm{wt} \% \\
n-\mathrm{BuOH} / \mathrm{xylene}=7 / 19(\mathrm{w} / \mathrm{w})\end{array}$ \\
\hline & & Macro NA-3 & $4.1 \times 10^{4}$ a) & 2.7 & $\begin{array}{l}C_{\mathrm{NA} /(n-\mathrm{BuOH}+\mathrm{xylene})}=0.61 \mathrm{wt} \% \\
n-\mathrm{BuOH} / \mathrm{xylene}=7 / 19(\mathrm{w} / \mathrm{w})\end{array}$ \\
\hline \multirow{4}{*}{ Top down } & \multirow{2}{*}{ Ball mill } & Macro NA-4 & $2.3 \times 10^{2}$ a) & 2.3 & \\
\hline & & Macro NA-5 & $7.9 \times 10^{2}$ a) & 1.5 & \\
\hline & Nanomizer & Macro NA-6 & $3.9 \times 10^{2}$ a) & 2.1 & \\
\hline & Jet mill & Macro NA-7 & $1.4 \times 10^{3}$ a) & 1.3 & \\
\hline
\end{tabular}

a) Measured by means of SEM. b) Degree of deviation, defined by eq 24. c) Measured by means of OM. d) Measured by WAXS. 


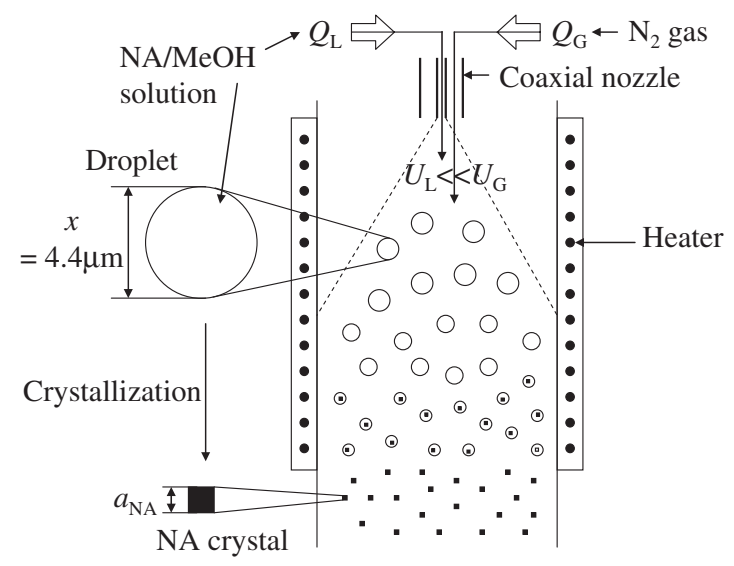

Figure 1. Schematic illustration of crystallization process of NA from NA/MeOH solution by spray drying method. $x=4.4$ $\mu \mathrm{m}$.

nozzle system, ${ }^{26}$ a droplet size $x$ is expressed by

$$
x=\frac{c_{1}}{U_{G}-U_{L}}+c_{2}\left(\frac{Q_{\mathrm{L}}}{Q_{\mathrm{G}}}\right)^{1.5}
$$

where $\mathrm{c}_{1}$ and $\mathrm{c}_{2}$ are constants, $U_{\mathrm{G}}$ and $U_{\mathrm{L}}$ are the flow velocity of gas and liquid, and $Q_{\mathrm{L}}$ and $Q_{\mathrm{G}}$ are the mass flow of liquid and gas, respectively.

In this study $x$ was fixed by selecting the following conditions,

$$
Q_{\mathrm{G}} \gg Q_{\mathrm{L}} \quad \text { and } \quad U_{\mathrm{G}} \gg U_{\mathrm{L}} .
$$

Therefore $x$ is approximated by

$$
x \cong \frac{c_{1}}{U_{\mathrm{G}}} .
$$

As $U_{G}=340 \mathrm{~ms}^{-1}, U_{L}=2 \mathrm{~ms}^{-1}, Q_{G}=3.4 \times 10^{-4}$ $\mathrm{m}^{3} \mathrm{~s}^{-1}$ and $Q_{L}=3.4 \times 10^{-7} \mathrm{~m}^{3} \mathrm{~s}^{-1}$ were fixed in this study, and $x$ became $4.4 \mu \mathrm{m}$. It will be shown that nano or macro NAs will be crystallized by controlling $C_{\mathrm{NA} / \mathrm{MeOH}}$. Typical $C_{\mathrm{NA} / \mathrm{MeOH}}$ for formation of nano NAs (named nano NA-1 and nano NA-2) and that of macro NAs (named macro NA-1 and macro NA-2) will be listed in Table II.

Bottom Up Method 2 (Solution Crystallization Method). NAs were crystallized from the solution of NA, $n$-butyl alcohol $(n$-BuOH) and xylene. The ratio of weight of $n-\mathrm{BuOH}$ and xylene was 7:19. Xylene was mixed to suppress diffusion of NA molecules. In the solution crystallization, ${ }^{27}$ driving force of crystallization is free energy of dissolution $(\Delta g)$ given by

$$
\begin{aligned}
\Delta g & =k T_{c} \ln \left(\frac{C_{\mathrm{NA} /(n-\mathrm{BuOH}+\mathrm{xylene})}}{C_{\mathrm{e}}}\right) \\
& =k T_{c} \ln (1+\Sigma)
\end{aligned}
$$

where $C_{\mathrm{NA} /(n-\mathrm{BuOH}+\mathrm{xylene})}$ is concentration of NA in the solution of NA, $n-\mathrm{BuOH}$ and xylene, $C_{\mathrm{e}}$ is saturated concentration of NA in the solution and $\Sigma$ is degree of supersaturation defined by

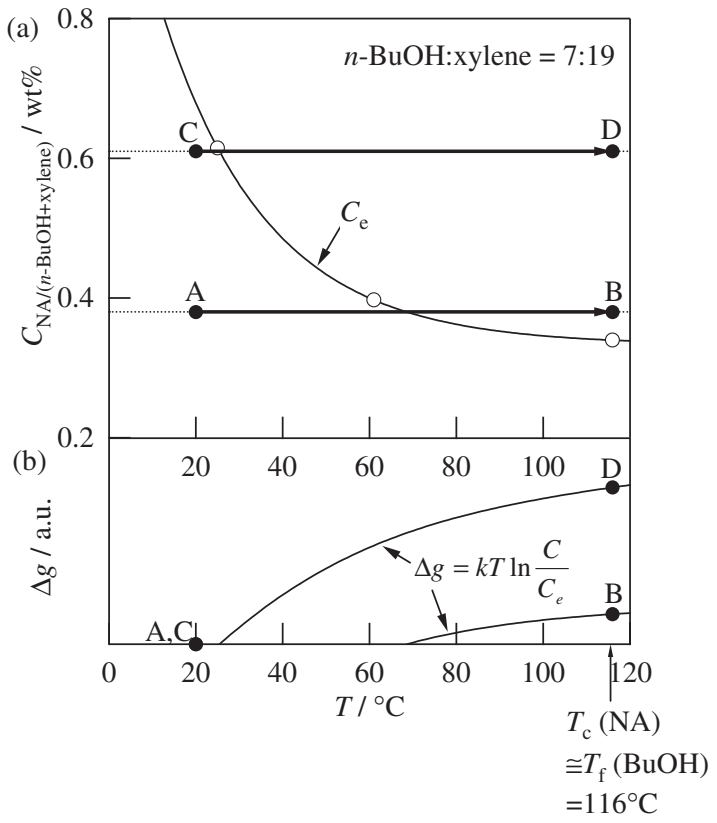

Figure 2. (a) $T$ dependence of $C_{\mathrm{e}}$ and crystallization processes in solution crystallization method, a $\mathrm{A} \rightarrow \mathrm{B}$ of nano NA (nano NA-3) at $C_{\mathrm{NA} /(n-\mathrm{BuOH}+\text { xylene })}=0.38 \mathrm{wt} \%$ and a $\mathrm{C} \rightarrow \mathrm{D}$ of macro NA (macro NA-3) at $C_{\mathrm{NA} /(n-\mathrm{BuOH}+\mathrm{xylene})}=0.61 \mathrm{wt} \%$. (b) $T$ dependence of $\Delta g$.

$$
\Sigma \equiv \frac{C_{\mathrm{NA} /(n-\mathrm{BuOH}+\text { xylene })}-C_{\mathrm{e}}}{C_{\mathrm{e}}} .
$$

Observed $C_{\mathrm{e}}$ was plotted in Figure 2a. $\Delta g$ is schematically illustrated in Figure $2 \mathrm{~b} . a_{\mathrm{NA}}$ decreased by decreasing $C_{\mathrm{NA} /(n-\mathrm{BuOH}+x y l e n e)}$. It will be shown that nano NA (named nano NA-3) or macro NA (macro NA-3) will be crystallized by increasing temperature $T$ from room temperature $T_{\mathrm{R}}$ to $T_{c}=116^{\circ} \mathrm{C}$, when $C_{\mathrm{NA} /(n-\mathrm{BuOH}+\text { xylene })}$ will be controlled to $0.38 \mathrm{wt} \%$ or $0.61 \mathrm{wt} \%$. The crystallization processes were indicated by $\mathrm{A} \rightarrow \mathrm{B}$ and $\mathrm{C} \rightarrow \mathrm{D}$ in Figure $2 \mathrm{a}$ and $2 \mathrm{~b}$, respectively. The macro NA (macro NA-3) was filtered at $T_{c}=116^{\circ} \mathrm{C}$ and then dried, while $a_{\mathrm{NA}}$ of nano NA will be shown to be too small to be filtered. Therefore nano NA was filtered and dried after coating by iPP crystals. For the coating, solution of iPP and xylene was added at $T_{c}=116^{\circ} \mathrm{C}$ and then quenched to $T_{\mathrm{R}}$.

Top Down Method (Mechanical Grinding Method). Large macro NA (macro NA-3) crystallized from solution was grinded by using conventional ball mill, jet mill (SEISHIN ENTERPRIZE Co., Ltd., Co-JET System $\alpha$-mkIII) or nanomizer (Nanomizer Co., Ltd., LA$31 \mathrm{NS}$ ). It will be shown that only macro NAs (named macro NA-4 $\sim 7$ ) will be obtained by grinding.

\section{Uniform Mixing of NA and iPP}

NA was uniformly mixed with solution of iPP and xylene at $T=130^{\circ} \mathrm{C}$. The suspension was quenched to $T_{\mathrm{R}}$, and dried. 


\section{Measurements}

Morphology of NA. Morphology of NA was observed by optical microscope (OM), OLYMPUS BX51 , and scanning electron microscope (SEM), Topcon SM-520.

Crystallization of iPP. Crystallization behaviors of iPP with NA were observed by using OM, OLYMPUS BX-51, with hotstage, LINKAM LK-600PM, under nitrogen flow of $50 \mathrm{~mL} / \mathrm{min}$. Temperature of hotstage was calibrated by using melting temperature of standard materials, indium $\left(156.6^{\circ} \mathrm{C}\right)$ and tin $\left(232^{\circ} \mathrm{C}\right)$. Sample was once melted at $210^{\circ} \mathrm{C}$ for $1 \mathrm{~min}$, and crystallized in the the range of $T_{c}=135-158^{\circ} \mathrm{C}$. $I$ was evaluated from time $t$ dependence of the number density of iPP crystals larger than $2 \mu \mathrm{m}$ in lateral size.

Unit Cell Structures of NA and iPP Crystals Mixed with Nano NA. Wide angle X-ray scattering (WAXS) measurement was conducted with Rigaku's RINT $2100 \mathrm{X}$-ray generator. The X-ray beam was $\mathrm{Cu} \mathrm{K} \alpha$ radiation $(\lambda=1.5418 \AA)$ from a rotating anode generator. The beam was monochromatized using a graphite crystal and focused by pin hole collimator $(\phi 0.3 \mathrm{~mm})$. The X-ray diffraction pattern was recorded on the imaging plate (Fuji Photo Film Co., Ltd, FDL-IP URV) which was read by imaging plate reader (Rigaku Denki Co., Ltd, R-AXIS DS3). The obtained image was analyzed by using the software (Rigaku Denki Co., Ltd, R-AXIS Display). After subtraction of background scattering from the air and amorphous of iPP, scattering intensity $I_{\mathrm{x}}(q)$ was obtained, where $q$ is wave vector.

Mean Lateral Size $\overline{a_{N A}}$ of NA Crystals. $a_{\mathrm{NA}}$ and distribution of $a_{\mathrm{NA}}\left(f\left(a_{\mathrm{NA}}\right)\right)$ were measured by means of SEM, OM or WAXS. Mean lateral size $\left(\overline{a_{\mathrm{NA}}}\right)$ is defined by

$$
\overline{a_{\mathrm{NA}}} \equiv \frac{\int a_{\mathrm{NA}} f\left(a_{\mathrm{NA}}\right) \mathrm{d} a_{\mathrm{NA}}}{\int f\left(a_{\mathrm{NA}}\right) \mathrm{d} a_{\mathrm{NA}}}
$$

Degree of deviation ( $s$ ) of $a_{\mathrm{NA}}$ is defined by

$$
s \equiv \frac{a_{\mathrm{max}}-\overline{a_{\mathrm{NA}}}}{\overline{a_{\mathrm{NA}}}}
$$

where $a_{\max }$ is the value of $a_{\mathrm{NA}}$ which satisfies following relation,

$$
\int_{a_{\max }}^{\infty} f\left(a_{\mathrm{NA}}\right) \mathrm{d} a_{\mathrm{NA}} / \int_{0}^{\infty} f\left(a_{\mathrm{NA}}\right) \mathrm{d} a_{\mathrm{NA}} \geq 1 \% .
$$

It will be shown that observation of $a_{\mathrm{NA}}$ of nano NA-3 by means of by SEM or OM will be impossible. Therefore $\overline{a_{\mathrm{NA}}}$ was obtained by WAXS by using Sherrer's method, ${ }^{28}$

$$
\overline{a_{\mathrm{NA}}}=\frac{0.9 \lambda}{B \cos \left\{\sin ^{-1}\left(\frac{q \lambda}{4 \pi}\right)\right\}}
$$

where $B$ is the net half width of a reflection given by

$$
B=\left(B_{\mathrm{obs}}^{2}-B_{\mathrm{s}}^{2}\right)^{\frac{1}{2}}
$$

where $B_{o b s}$ and $B_{s}$ are the half width of reflection of the sample and collimator system, respectively. $B_{s}$ was determined by the reflection of the powder of lithium fluoride macroscopic crystals.

$C_{N A} . \quad C_{\mathrm{NA}}$ of nano NA-3 was determined from $I_{\mathrm{x}}(q)$ s of NA and iPP crystals. $C_{\mathrm{NA}}$ is given by eq A.3,

$$
C_{\mathrm{NA}}=\frac{1}{\gamma \frac{I_{\mathrm{x}}(i P P)_{\mathrm{NA} / \mathrm{iPP}}}{I_{\mathrm{x}}(\mathrm{NA})_{\mathrm{NA} / \mathrm{iPP}}}+1}
$$

where $I_{\mathrm{x}}(\mathrm{iPP})_{\mathrm{NA} / \mathrm{iPP}}$ and $I_{\mathrm{x}}(\mathrm{NA})_{\mathrm{NA} / \mathrm{iPP}}$ are $I_{\mathrm{x}}(q)$ of 110 of iPP and 200 of NA in the mixture of nano NA-3 and iPP. $\gamma$ is shown in eq A.5.

\section{RESULTS AND DISCUSSION}

\section{Size and Morphology of NA}

Bottom Up Method 1 (Spray Drying Method). $a_{\mathrm{NA}}$ observed by means of SEM or OM apparently increased from the order of $10 \mathrm{~nm}$ to $1 \mu \mathrm{m}$ with increase of $C_{\mathrm{NA} / \mathrm{MeOH}}$ from $10^{-5}$ to $34 \mathrm{wt} \%$, that showed formation of nano NA (nano NA-1) and macro NA (macro NA-2) as shown in Figure 3. The nano and macro NAs showed square plate like morphology. $\overline{a_{\mathrm{NA}}}$ of them obtained from eq 23 were $26 \mathrm{~nm}$ and $4.5 \mu \mathrm{m}$, respectively. $f\left(a_{\mathrm{NA}}\right)$ of them were $s=0.73$ and 0.44 as shown in Figure $3 \mathrm{c}$ and $3 \mathrm{~d}$, which showed much narrower distribution than that prepared by "top down" method which will be shown in Figure $7 \mathrm{c}$ and $7 \mathrm{~d}$.

$\overline{a_{\mathrm{NA}}}$ was plotted against $C_{\mathrm{NA} / \mathrm{MeOH}}$ in Figure 4 . The plots well fitted a straight line and the slope was $1 / 3$. Therefore eq 17 was confirmed experimentally.

Bottom Up Method 2 (Solution Crystallization Method). When $C_{\mathrm{NA} /(n-\mathrm{BuOH}+\text { xylene })}$ was increased from 0.38 to $0.61 \mathrm{wt} \%$, formation of nano NA (nano NA-3) and macro NA (macro NA-3) were confirmed by means of WAXS and SEM, respectively, as shown below. When the nano NA was mixed with iPP, any NAs could not be detected within the melt of iPP by means of $\mathrm{OM}$ at $T=210^{\circ} \mathrm{C}$ as shown in Figure 5a, which indicates that the $a_{\mathrm{NA}}$ should be less than $0.1 \mu \mathrm{m}$ in order. Therefore $\overline{a_{\mathrm{NA}}}$ of nano NA-3 was obtained by WAXS applying eq 26 from half width $\left(B_{\text {obs }}\right)$ of 200 reflection as indicated in Figure 6a. The $\overline{a_{\mathrm{NA}}}$ was as small as $5 \mathrm{~nm}$.

Morphology and $f\left(a_{\mathrm{NA}}\right)$ of macro NA were thin long plate like and broad as shown in Figure $5 \mathrm{~b}$ and 
(a)

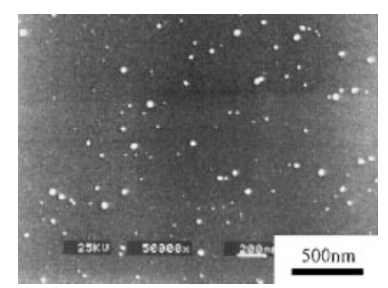

(b)

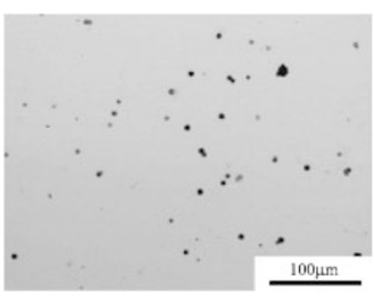

(c)

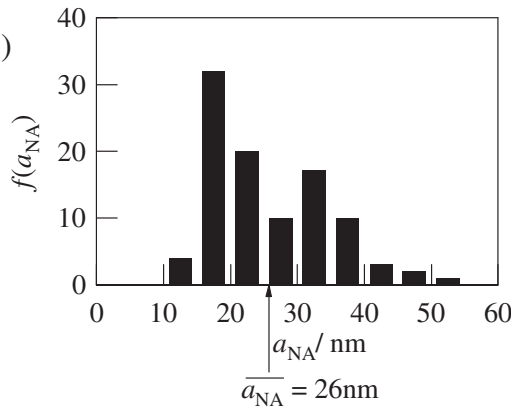

(d)

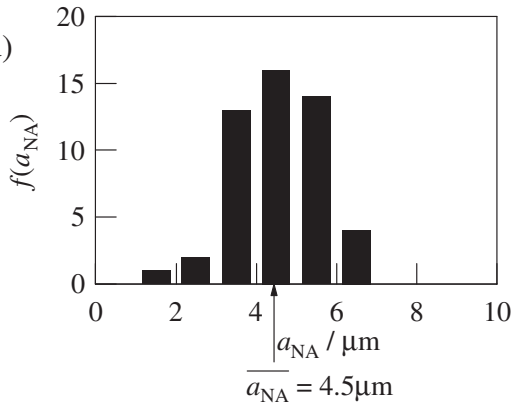

Figure 3. Morphology and $f\left(a_{\mathrm{NA}}\right)$ of nano NA (nano NA-1) and macro NA (macro NA-2) crystallized by spray drying method. $U_{G}=340 \mathrm{~ms}^{-1}, U_{L}=2 \mathrm{~ms}^{-1}, Q_{G}=3.4 \times 10^{-4} \mathrm{~m}^{3} \mathrm{~s}^{-1}$ and $Q_{L}=3.4 \times 10^{-7} \mathrm{~m}^{3} \mathrm{~s}^{-1}$ were fixed. Nano NA and macro NA were crystallized by controlling $C_{\mathrm{NA} / \mathrm{MeOH}}=10^{-5}$ and $34 \mathrm{wt} \%$, respectively. (a) Typical scanning electron micrograph of nano NA. (b) Typical optical micrograph of macro NA. (c) $f\left(a_{\mathrm{NA}}\right)$ and $\overline{a_{\mathrm{NA}}}$ of nano NA. (d) $f\left(a_{\mathrm{NA}}\right)$ and $\overline{a_{\mathrm{NA}}}$ of macro NA.

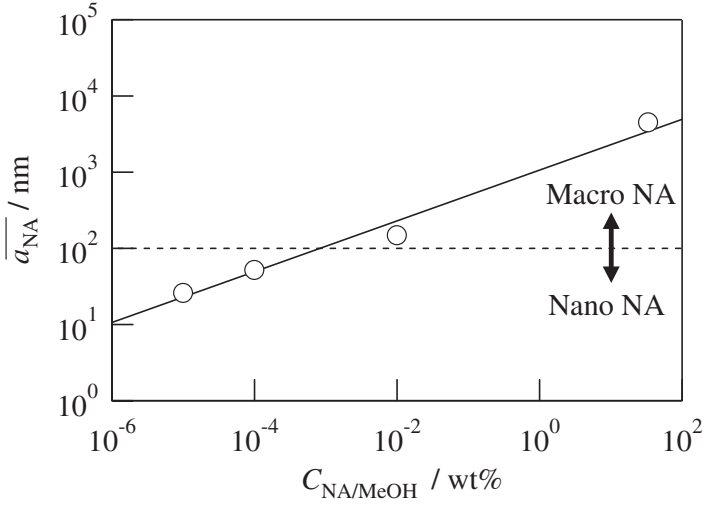

Figure 4. Plots of $\overline{a_{\mathrm{NA}}}$ of nano and macro NAs (nano NA-1, nano NA-2, macro NA-1 and macro NA-2) crystallized by spray drying method against $C_{\mathrm{NA} / \mathrm{MeOH}} x$ was $4.4 \mu \mathrm{m}$. 5c, respectively. $\overline{a_{\mathrm{NA}}}=41 \mu \mathrm{m}$ was obtained. Aspect ratio between length and width was as large as 20-40.

Top Down Method (Mechanical Grinding Method). Only macro NAs (named macro NA-4 $\sim 7$ ) were obtained, i.e., nano NAs were hardly obtained, by grinding large macro NA single crystals (macro NA-3). This is shown in Table II. Figure $7 \mathrm{a}$ and $7 \mathrm{~b}$ show typical SEM photographs of them (macro NA-4 and macro NA-5). $f\left(a_{\mathrm{NA}}\right)$ of them showed broad distribution as shown in Figure 7c and 7d, and $s=2.3$ and 1.5, respectively. Therefore it is concluded that the $f\left(a_{\mathrm{NA}}\right)$ prepared by top down method was much broader than that of NAs crystallized by bottom up method ( $s=$ $0.33-0.8)$ as shown in Table II. $\overline{a_{\mathrm{NA}}}$ was from the order of sub $\mu \mathrm{m}$ to $\mu \mathrm{m}$. It is to be noted that morphology (a)

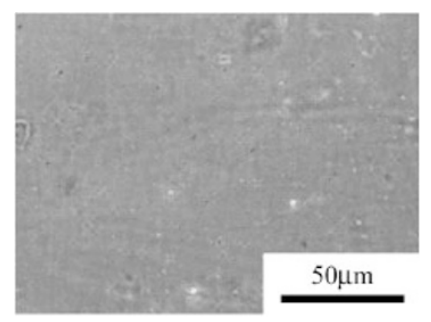

(b)

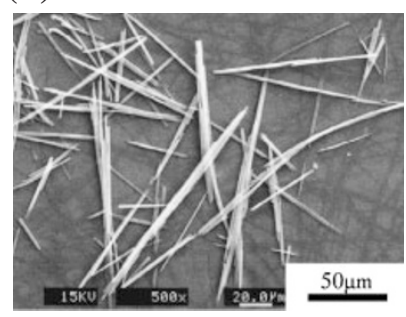

(c)

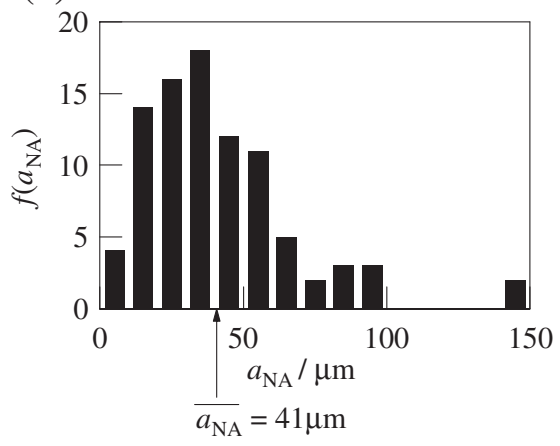

Figure 5. Morphologies and $f\left(a_{\mathrm{NA}}\right) \mathrm{s}$ of nano NA (nano NA-3, $C_{\mathrm{NA} /(n-\mathrm{BuOH}+\mathrm{xylene})}=0.38 \mathrm{wt} \%$ ) and macro NA (macro NA-3, $\left.C_{\mathrm{NA} /(n-\mathrm{BuOH}+\mathrm{xylene})}=0.61 \mathrm{wt} \%\right)$ crystallized by solution crystallization method. (a) Typical optical micrograph of iPP with nano NA was observed in the melt of iPP at $T=210^{\circ} \mathrm{C}$. (b) Typical scanning electron micrograph of macro NA and (c) $f\left(a_{\mathrm{NA}}\right)$ and $\overline{a_{\mathrm{NA}}}$ of macro NA. 
of macro NAs was rectangular shape with smooth facet. Aspect ratio was about 1 to 8 , which was $1 / 10$ in order as small as that of large macro NA. This indicates that the long NA single crystals were easily broken by grinding perpendicular to the long axis and cleaved along the long axis showing smooth facet by grinding. Therefore epitaxial lattice planes of macro NA single crystals should be conserved.

Unit Cell Structures of Nano NA and iPP Crystals. Unit cell structure of nano NA (nano NA-3) was determined as $\alpha$ form ${ }^{15}$ by WAXS, because the diffraction pattern of nano NA was the same as that of macro NA (macro NA-4) in the range of $q=0.3$ to $0.7 \AA^{-1}$, which are shown in Figure 6a and 6b. Magnified diffraction pattern is shown at the upper left in Figure $6 \mathrm{a}$. Unit cell structure of iPP mixed with nano NA was $\alpha$ form, because the diffraction pattern was the same as that of $\alpha$ form crystals of iPP in the range of $q=0.7$ to $1.8 \AA^{-1}$, which is shown in Figure 6a and $6 \mathrm{c}$. The additional reflections were attributed to those of NA.

$C_{N A}$ of Nano NA (Solution Crystallization Method). $C_{\mathrm{NA}}$ of iPP mixed with nano NA (nano NA-3) was determined by WAXS applying eq 28. $I_{\mathrm{x}}(q) \mathrm{s}$ of 200 of $\mathrm{NA}$ and 110 of iPP $\left(I_{\mathrm{x}}(\mathrm{NA})_{\mathrm{NA} / \mathrm{iPP}}\right.$ and $I_{\mathrm{x}}(\mathrm{iPP})_{\mathrm{NA} / \mathrm{iPP}}$, respectively) were obtained from hatched area in Figure 6a. $C_{\mathrm{NA}}=1.4 \mathrm{wt} \%$ was obtained.

\section{Crystallization Behaviors of iPP Mixed with Nano} and Macro NAs

$I$ (nano NA) and $I$ (macro NA) were compared by means of $\mathrm{OM}$ for the same $C_{\mathrm{NA}}$ and $\Delta T, C_{\mathrm{NA}}=1.4$

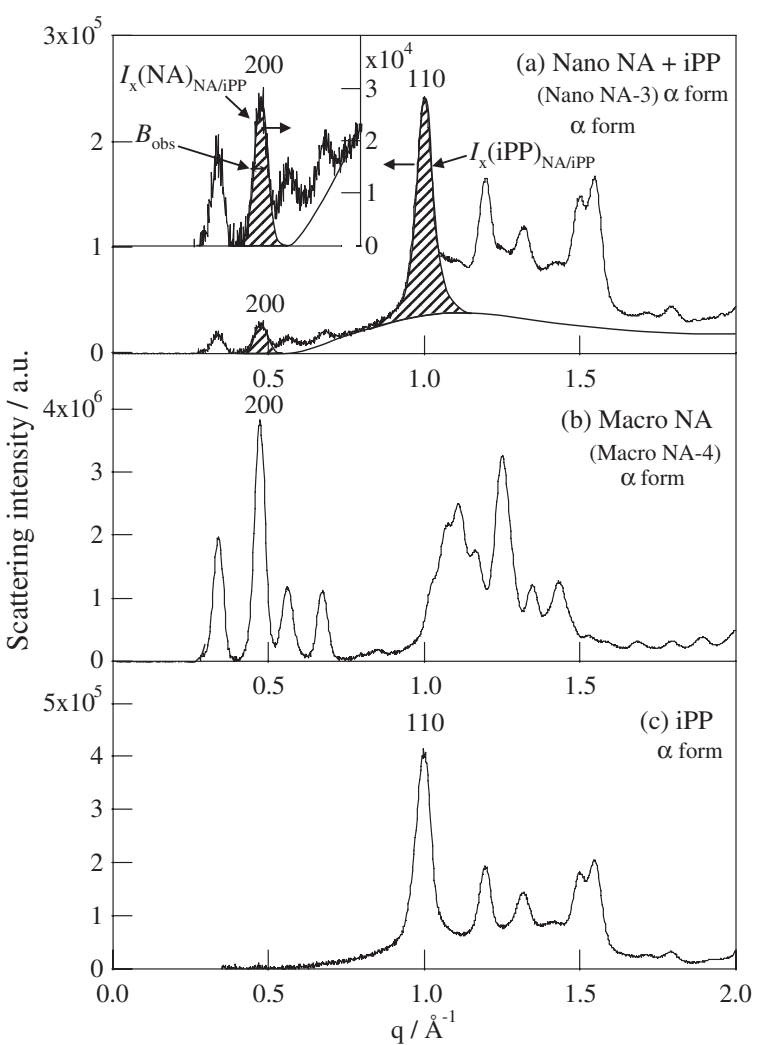

Figure 6. WAXS diffraction patterns at $T_{\mathrm{R}}$ of (a) nano NA (nano NA-3) in the mixture of NA and iPP, (b) $\alpha$ form of macro NA (macro NA-4) and (c) $\alpha$ form of iPP. The hatched reflections were analyzed to determine $\overline{a_{\mathrm{NA}}}$ and $C_{\mathrm{NA}}$. (a)

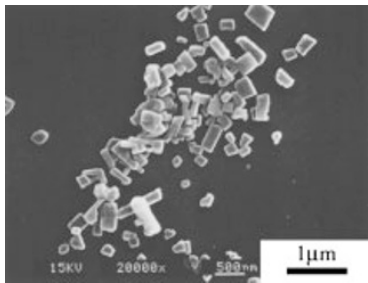

(b)

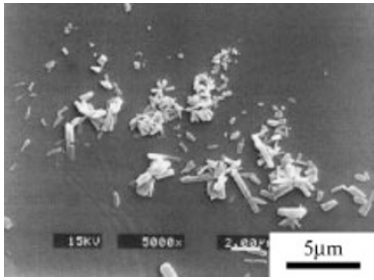

(c)

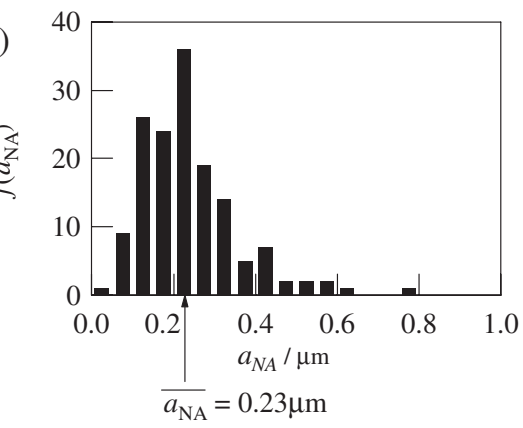

(d)

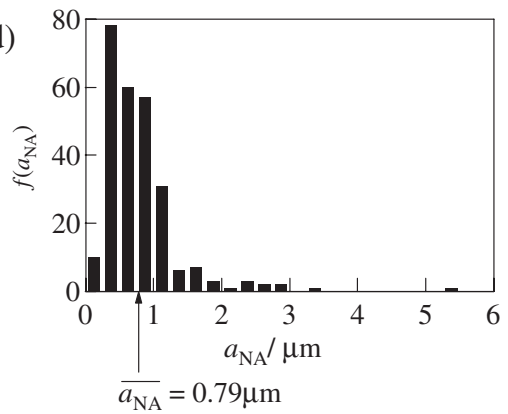

Figure 7. Morphologies and $f\left(a_{\mathrm{NA}}\right)$ of macro NAs prepared by top down method. Scanning electron micrographs of (a) macro NA-4 and (b) macro NA-5, and $f\left(a_{\mathrm{NA}}\right)$ and $\overline{a_{\mathrm{NA}}}$ of (c) macro NA-4 and (d) macro NA-5. 


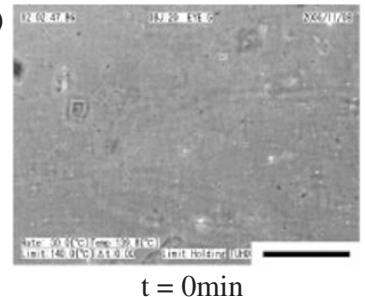

(c)

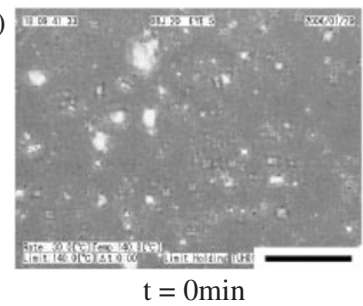

(b)

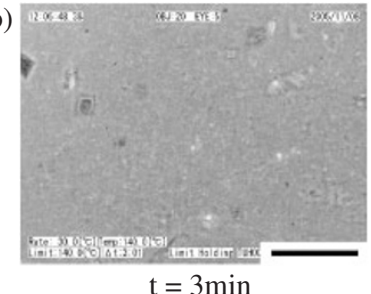

(d)

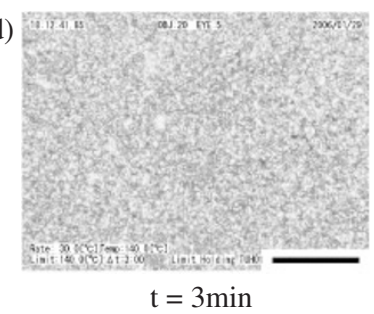

Figure 8. Typical isothermal crystallization behaviors of iPP mixed with the same $C_{\mathrm{NA}}=1.4 \mathrm{wt} \%$. (a) and (b) show before and after crystallization of nano NA (nano NA-3) and (c) and (d) do that of macro NA (macro NA-4) at $T_{c}=138.8^{\circ} \mathrm{C}$. $\mathrm{t}$ indicates crystallization time. Scale bar is $50 \mu \mathrm{m}$.

wt $\%$ and $\Delta T=43.8 \mathrm{~K}\left(T_{c}=138.8^{\circ} \mathrm{C}\right)$ as shown in Figure 8. In the case of crystallization of iPP mixed with nano NA (nano NA-3), OM photograph of after completion of crystallization $(\mathrm{t}=3 \mathrm{~min})$ shown in Figure $8 \mathrm{~b}$ did not change in comparison with that of supercooled melt $(\mathrm{t}=0 \mathrm{~min})$ shown in Figure 8a. This indicates that the size of iPP crystals $a$ should be smaller than the wave length of light $\lambda(\lambda=0.1$ $\mu \mathrm{m}$ in order). Details of the crystallization behavior will be reported in the subsequent paper. In the case of iPP mixed with macro NA (macro NA-4), obvious difference was observed in OM photographs in Figure $8 \mathrm{c}$ and $8 \mathrm{~d}$, which shows before and after completion of crystallization. The size of iPP crystals was larger than $\mu \mathrm{m}$ in order. Therefore it is concluded qualitatively that

$$
I(\text { nano NA }) \gg I(\text { macro } \mathrm{NA}) \text {. }
$$

\section{$C_{N A}$ Dependence of $I_{0}$}

The above conclusion of eq 29 , i.e., I(nano NA) $\gg$ I(macro NA), was quantitatively confirmed. $\log I$ of iPP mixed with nano or macro NAs (nano NA-3 or macro NA-4, respectively) was plotted against $\Delta T^{-1}$ as a parameter of $C_{\mathrm{NA}}$ in Figure 9. Upper horizontal axis indicates $T_{c}$. All plots fitted straight lines. As all slopes of the lines were almost the same, averaged slope was applied to all the fitted lines. $I_{0}$ was obtained from an intercept of the vertical axis. The lines shifted to upward at a $\Delta T^{-1}$ with increase of $C_{\mathrm{NA}}$ for a constant $\overline{a_{\mathrm{NA}}}$.

$\log I_{0}$ s were plotted against $C_{\mathrm{NA}}$ in Figure 10 for nano and macro NAs (nano NA-3 and macro NA-4). Both plots well fitted straight lines and the slopes of

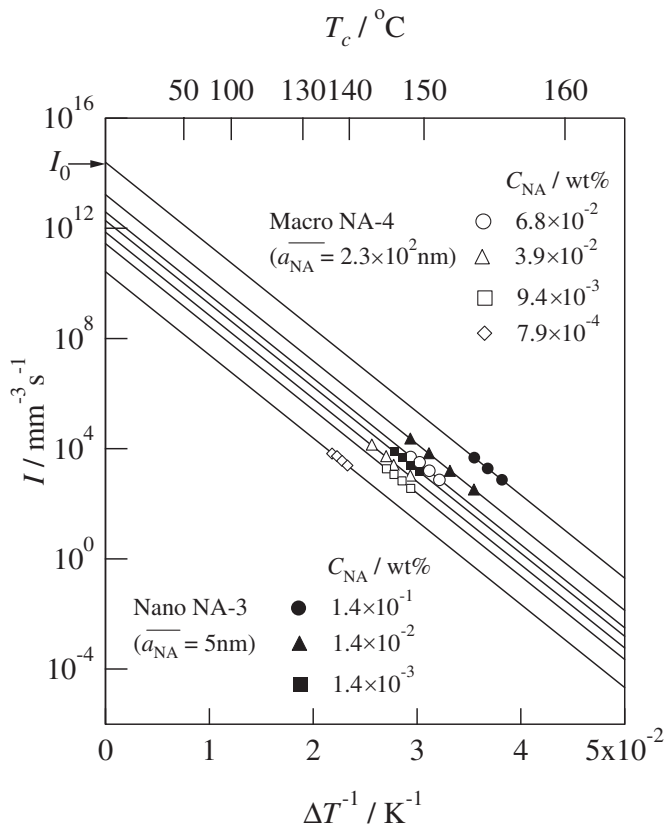

Figure 9. Plots of $I$ s against $\Delta T^{-1}$ as a parameter of $C_{\mathrm{NA}}$ of iPP mixed with nano NA (nano NA-3, $\overline{a_{\mathrm{NA}}}=5 \mathrm{~nm}$ ) and macro NA (macro NA-4, $\overline{a_{\mathrm{NA}}}=2.3 \times 10^{2} \mathrm{~nm}$ ). Upper axis indicates $T_{c}$.

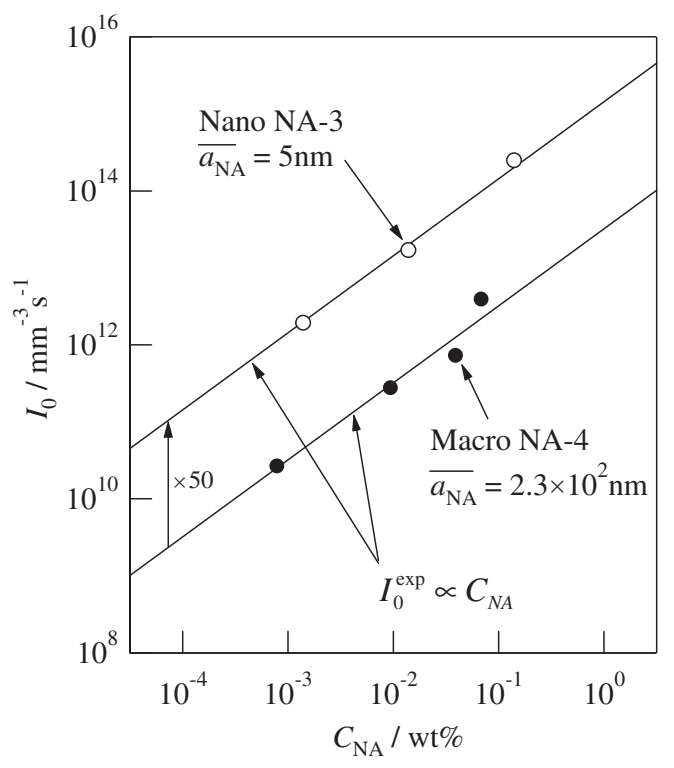

Figure 10. Plots of $I_{0} \mathrm{~s}$ against $C_{\mathrm{NA}}$ of iPP mixed with nano NA (nano NA-3) and macro NA (macro NA-4). Experimental formula, $I_{0}^{\exp } \propto C_{\mathrm{NA}}$ was obtained.

them were 1 . Therefore experimental formula of $I_{0}$ $\left(I_{0}^{\exp }\right)$,

$$
I_{0}^{\exp } \propto C_{\mathrm{NA}}
$$

was obtained. This satisfies eq 10. $I_{0}$ of iPP mixed with nano NA ( $I_{0}$ (nano NA-3)) was 50 times as large as that mixed with macro NA ( $I_{0}($ macro NA-4)) for the same $C_{\mathrm{NA}}$. As $\overline{a_{\mathrm{NA}}}$ of macro NA $\left(\overline{a_{\mathrm{NA}}}(\right.$ macro NA-4)) was 50 times as large as that of nano NA 


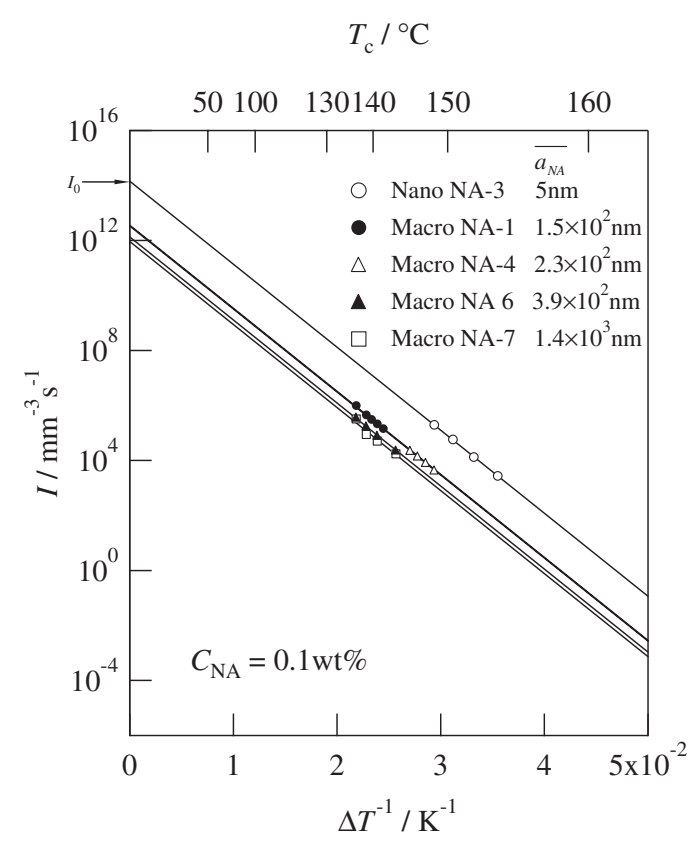

Figure 11. Plots of $I$ s against $\Delta T^{-1}$ for $C_{\mathrm{NA}}=0.1 \mathrm{wt} \%$ as a parameter of $\overline{a_{\mathrm{NA}}}$. Nano NA (nano NA-3) and macro NAs (macro NA-1, macro NA-4, macro NA-6 and macro NA-7) were used. Upper axis indicates $T_{c}$.

$\left(\overline{a_{\mathrm{NA}}}(\right.$ nano $\left.\mathrm{NA}-3)\right)$, we have

$I_{0}$ (nano NA-3) $/ I_{0}$ (macro NA-4)

$$
=\overline{a_{\mathrm{NA}}}\left(\text { macro NA-4) } / \overline{a_{\mathrm{NA}}}(\text { nano NA}-3)=50\right. \text {. }
$$

Thus we have experimental relationship $I_{0} \propto{\overline{a_{N A}}}^{-1}$, which satisfies eq 10 .

It was reported by part of present authors (Hikosaka et al.) that $I$ of PE mixed with $3 \mathrm{wt} \% \mathrm{NA}$ is ten thousand times as large as $I$ of PE without mixing NA. ${ }^{3}$ Therefore the proposed relationship in eq 10 is expected to be valid for any polymers. The universality of eq 10 for any NAs will be soon reported in our succeeding paper by showing increase of $I$ of iPP mixed with three NAs.

$a_{N A}$ Dependence of $I_{0} . \quad \log I$ was plotted against $\Delta T^{-1}$ as a parameter of $\overline{a_{\mathrm{NA}}}$ for $C_{\mathrm{NA}}=0.1 \mathrm{wt} \%$ in Figure 11. Upper horizontal axis indicates $T_{c}$. The plots well fitted straight lines. As all fitted lines were nearly parallel, averaged slope was applied. $I_{0}$ was obtained from an intercept of the vertical axis. As the lines shifted upward at a $\Delta T^{-1}$ with decrease of $\overline{a_{\mathrm{NA}}}$ for a constant $C_{\mathrm{NA}}, I_{0}$ increased with decrease of $\overline{a_{\mathrm{NA}}}$.

$\log I_{0}$ was plotted against $\overline{a_{\mathrm{NA}}}$ for $C_{\mathrm{NA}}=0.1 \mathrm{wt} \%$ in Figure 12. The plots well fitted a straight line and the slope of the line was -1 . Experimental formula of $I_{0}^{\exp }$,

$$
I_{0}^{\exp } \propto{\overline{a_{\mathrm{NA}}}}^{-1}
$$

was obtained. This formula satisfies the eq 10. A typical example shows in Figure 12A and 12B that

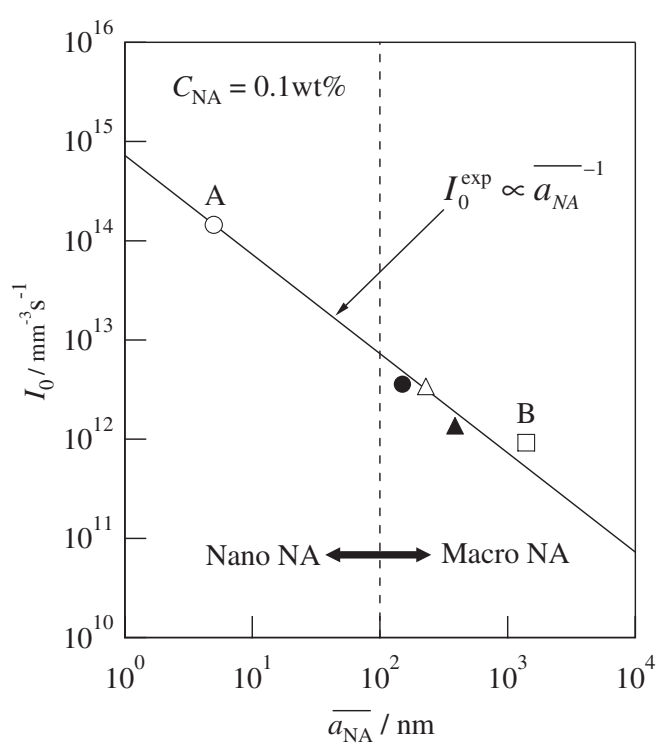

Figure 12. Plots of $I_{0} \mathrm{~s}$ against $\overline{a_{\mathrm{NA}}}$ for $C_{\mathrm{NA}}=0.1 \mathrm{wt} \%$. Nano NA (nano NA-3) and macro NAs (macro NA-1, macro NA-4, macro NA-6 and macro NA-7) were used. Experimental formula, $I_{0}^{\exp } \propto{\overline{a_{N A}}}^{-1}$ was obtained.

$I_{0}$ (nano NA-3) $\left(\overline{a_{\mathrm{NA}}}=5 \mathrm{~nm}\right)$ was 300 times as large as $I_{0}$ (macro NA-7) $\left(\overline{a_{\mathrm{NA}}}=1.4 \mu \mathrm{m}\right)$.

\section{Confirmation of the Prediction}

Combination of experimental formulae of $I_{0}^{\exp }$, eqs 30 and 32 gives

$$
I_{0}^{\exp } \propto \frac{C_{\mathrm{NA}}}{\overline{a_{\mathrm{NA}}}} .
$$

Therefore the prediction of eq 10 was experimentally confirmed. $I_{0}$ of iPP mixed with nano NA $\left(\overline{a_{\mathrm{NA}}}=5\right.$ $\mathrm{nm}$ ) was 50 to $10^{3}$ times as large as that mixed with conventional commercial NA $\left(\overline{a_{\mathrm{NA}}}=0.2-5 \mu \mathrm{m}\right)$. Therefore nano-sizing of NA is significantly effective method to improve the nucleating ability of NA.

\section{CONCLUSIONS}

1. Theoretical prediction proposed in our previous study $^{3}$ that $I \propto C_{\mathrm{NA}} a_{\mathrm{NA}}{ }^{-1}$ was experimentally confirmed on iPP, where $I$ is nucleation rate of polymer crystals, $C_{\mathrm{NA}}$ is concentration of NA in the mixture of NA and polymers and $a_{\mathrm{NA}}$ is the longest lateral size of NA crystal. $a_{\mathrm{NA}}$ and $C_{\mathrm{NA}}$ were changed in order from $\mathrm{nm}$ to $\mu \mathrm{m}$ and from $10^{-3}$ to $1 \mathrm{wt} \%$, respectively. The above confirmation clarified our proposal that epitaxy between NA and polymer crystals takes the most important role in acceleration mechanism of nucleation of polymers.

2. Decreasing $a_{\mathrm{NA}}$ from $\mu \mathrm{m}$ to $\mathrm{nm}$ in order and narrowing distribution of $a_{\mathrm{NA}} f\left(a_{\mathrm{NA}}\right)$ are effective methods to develop high-performance NA, which is an important guidance to polymer industry. 
3. Nano-sized NA with sharp distribution could be obtained by bottom up methods, but could not be done by top down methods. Therefore it is concluded that bottom up method is the best method to making nano-sized NA with sharp $f\left(a_{\mathrm{NA}}\right)$.

\section{REFERENCES}

1. J. Kurja and N. A. Mehl, in "Plastics Additives Handbook," 5th ed., H. Zweifel, Ed., Hanser, Munich, 2001, chap. 18, p 949.

2. B. Fillon, B. Lotz, A. Thierry, and J. C. Wittmann, J. Polym. Sci., Part B: Polym. Phys., 31, 1395 (1993).

3. M. Hikosaka, S. Yamazaki, I. Wataoka, N. Ch. Das, K. Okada, A. Toda, and K. Inoue, J. Macromol. Sci., Part B: Phys., 42, 847 (2003).

4. F. P. Price, in "Nucleation," A. C. Zettlemoyer, Ed., Marcel Dekker, New York, 1969, chap. 8, p 405.

5. H. N. Beck, J. Appl. Polym. Sci., 11, 673 (1967).

6. F. L. Binsbergen, Polymer, 11, 253 (1970).

7. K. Ikeda, Kobunshi Ronbunshu, 44, 539 (1987).

8. T. Kobayashi, M. Takemoto, and T. Hashimoto, Kobunshi Ronbunshu, 55, 613 (1998).

9. S. Yamasaki, Y. Ohashi, H. Tsutsumi, and K. Tsuji, Bull. Chem. Soc. Jpn., 68, 146 (1995).

10. M. Watase and H. Itagaki, Bull. Chem. Soc. Jpn., 71, 1457 (1998).

11. S. Yan, F. Katzenberg, J. Petermann, D. Yang, Y. Shen, C. Straupe, J. C. Wittmann, and B. Lotz, Polymer, 41, 2613 (2000)

12. J. C. Wittmann and B. Lotz, J. Polym. Sci., Polym. Phys. Ed., 19, 1837 (1981).

13. J. C. Wittmann, A. M. Hodge, and B. Lotz, J. Polym. Sci., Polym. Phys. Ed., 21, 2495 (1983).

14. H. G. Haubruge, R. Daussin, A. M. Jonas, R. Legras, J. C. Witmann, and B. Lotz, Macromolecules, 36, 4452 (2003).

15. S. Yoshimoto, T. Ueda, K. Yamanaka, A. Kawaguchi, E. Tobita, and T. Haruna, Polymer, 42, 9627 (2001).

16. D. Turnbull and J. C. Fisher, J. Chem. Phys., 17, 71 (1949).

17. K. Okada, K. Watanabe, T. Urushihara, A. Toda, and M. Hikosaka, Polymer, in press.

18. S. Nagasawa, A. Fujimori, T. Masuko, and M. Iguchi, Polymer, 46, 5241 (2005).

19. T. Sugimoto, in "Engineering System for Fine Particles, Fundamental Technology I," H. Yanagida, Ed., Fuji Techno System, Tokyo, 2001, chap. 5, p 656.

20. H. Imai, in "Biryushi handobukku," G. Jinbo, E. Ozawa, Y. Kousaka, H. Komiyama, M. Sadakata, A. Yoshizawa, Ed., Asakura publishing, Tokyo, 1991, chap. 4, p 304.

21. K. Hayashi, M. Hikosaka, A. Toda, and P. Maiti, Polym. Prepr., Jpn., 47, 3821 (1998).

22. J. Brandrup, E. H. Immergut, D. R. Bloch and E. A. Grulke, in "Polymer Handbook," 4th ed., John Wiley \& Sons, New York, 2003, V/23.

23. J. J. Janimak, S. Z. D. Cheng, and P. A. Giusti, Macromolecules, 24, 2253 (1991).

24. K. Yamada, M. Hikosaka, A. Toda, S. Yamazaki, and K. Tagashira, Macromolecules, 36, 4790 (2003).

25. K. Yamada, M. Hikosaka, A. Toda, S. Yamazaki, and K. Tagashira, Macromolecules, 36, 4802 (2003).

26. S. Nukiyama and Y. Tanasawa, Nihon Kikaigakkai Ronbunshu, 5, 68 (1939).

27. T. Kuroda, in "Kesshouwa ikiteiru," Saiensu-sha, Tokyo, 1984, chap. 3, p 85.

28. I. Nitta, in "X-senn kesshougaku, II," Maruzen, Tokyo, 1959, chap. IV, p 490.

\section{APPENDIX}

Determination of $C_{N A}$ by WAXS

$C_{\mathrm{NA}}$ is defined by

$$
C_{\mathrm{NA}} \equiv \frac{W(\mathrm{NA})_{\mathrm{NA} / \mathrm{iPP}}}{W(\mathrm{NA})_{\mathrm{NA} / \mathrm{PP}}+W(\mathrm{iPP})_{\mathrm{NA} / \mathrm{iPP}}}
$$

where $W(\mathrm{NA})_{\mathrm{NA} / \mathrm{iPP}}$ and $W(\mathrm{iPP})_{\mathrm{NA} / \mathrm{PPP}}$ are weight of NA and iPP in mixture of NA and iPP where X-ray irradiated. They are estimated from scattering intensity of NA and iPP, $I_{\mathrm{x}}(\mathrm{NA})_{\mathrm{NA} / \mathrm{iPP}}$ and $I_{\mathrm{x}}(\mathrm{iPP})_{\mathrm{NA} / \mathrm{iPP}}$,

$$
W(\mathrm{NA})_{\mathrm{NA} / \mathrm{PPP}}=\alpha I_{\mathrm{x}}(\mathrm{NA})_{\mathrm{NA} / \mathrm{iPP}}
$$

and

$$
W(\mathrm{iPP})_{\mathrm{NA} / \mathrm{iPP}}=\beta I_{\mathrm{x}}(\mathrm{iPP})_{\mathrm{NA} / \mathrm{iPP}}
$$

where $\alpha$ and $\beta$ are constants. Combination of (A.1) and (A.2) gives,

$$
C_{\mathrm{NA}}=\frac{1}{\gamma \frac{I_{\mathrm{x}}(\mathrm{iPP})_{\mathrm{NA} / \mathrm{iPP}}}{I_{\mathrm{x}}(\mathrm{NA})_{\mathrm{NA} / \mathrm{iPP}}}+1}
$$

where $\gamma=\beta / \alpha$. As the scattering intensity of NA and iPP $\left(I_{\mathrm{x}}(\mathrm{NA})\right.$ and $\left.I_{\mathrm{x}}(\mathrm{PPP})\right)$ and the weight of NA and iPP ( $W(\mathrm{NA})$ and $W(\mathrm{iPP}))$ where $\mathrm{X}$-ray irradiated satisfy the same equation as eq A.2,

$$
\frac{I_{\mathrm{x}}(N A)}{I_{\mathrm{x}}(i P P)}=\frac{\frac{1}{\alpha} W(N A)}{\frac{1}{\beta} W(i P P)} \equiv \gamma \frac{W(N A)}{W(i P P)}
$$

is obtained. Thus we have

$$
\gamma=\frac{I_{\mathrm{x}}(N A)}{I_{\mathrm{x}}(i P P)} \frac{W(i P P)}{W(N A)} .
$$

